\title{
Cigarette purchase patterns in four countries and the relationship with cessation: findings from the International Tobacco Control (ITC) Four Country Survey
}

\author{
A Hyland, F L Laux, C Higbee, G Hastings, H Ross, F J Chaloupka, G T Fong, K M Cummings
}

Tobacco Control 2006;15(Suppl III):iii59-iii64. doi: 10.1136/tc.2005.012203

See end of article for authors' affiliations

Correspondence to K Michael Cummings, $\mathrm{PhD}, \mathrm{MPH}$, Roswell Park Cancer Institute, Department of Health Behavior, Elm and Carlton Streets, Buffalo, New York 14263, USA; michael. cummings@roswellpark. org

Received 19 April 2005 Accepted 19 October 2005
Background: Higher cigarette prices result in decreased cigarette consumption, but some smokers may seek lower-taxed cigarette sources. This price avoidance behaviour likely dampens the health impact of higher cigarette prices although it has not been thoroughly studied.

Objective: To describe the characteristics of smokers who purchase low/untaxed cigarettes and to examine how this behaviour is associated with subsequent changes in smoking behaviours.

Methods: Telephone survey data from 8930 smokers from the International Tobacco Control (ITC) Four Country Survey (ITC-4) were used to assess cigarette purchase patterns and smoking behaviours in Wave 1 conducted from October to December 2002 and subsequently followed seven months later in Wave 2. Respondents' smoking status, attempts to quit, amount smoked, and cigarette purchase patterns were assessed in both waves.

Results: Rates of purchase from a low/untaxed source at the respondents' last cigarette purchase differed notably between countries at Wave 1, from less than 1\% in Australia to 15\% in the United Kingdom. In the UK, but not the other countries, this increased significantly to $20 \%$ at Wave 2 . Smokers who were older, white/English speakers, had higher incomes, and had higher levels of education were more likely to report purchasing cigarettes from a low/untaxed source on their last purchase. Those who reported purchasing from a low/untaxed source on their last purchase at Wave 1 were less likely to have tried to quit smoking quit smoking by Wave 2 (relative risk $0.70, \mathrm{p}<0.01$ ), while no overall significant association with smoking cessation was observed.

Conclusion: Data from this study indicate that there are lower levels of making a quit attempt among purchasers of low/untaxed cigarettes compared to purchasers of full-priced cigarettes. The availability of low/untaxed cigarettes may mitigate the influence of increases in cigarette prices.
$\mathrm{H}$ igher cigarette prices result in a decrease in cigarette consumption and smoking prevalence. ${ }^{12}$ However, smokers have an increasing array of lower priced purchase options to switch to when prices increase, including low/untaxed cigarettes from other sources such as the internet and cross-border sales ${ }^{3}$ as well as discount/generic cigarettes. ${ }^{3}$ The combination of a wide range in cigarette prices and the emergence of the internet and other readily available sources to purchase low/untaxed cigarettes has created unprecedented opportunities for smokers to purchase lower taxed and lower priced cigarettes. Relatively little is known how prevalent these behaviours are and what impact they have on smoking cessation indicators.

Several studies have assessed the impact of cigarette smuggling on cigarettes sales and smoking behaviour. Yurekli and Zhang found that in 1995 the net revenue lost by states due to smuggling was $\$ 317$ million $(\sim 6 \%$ of the states' tax revenues). ${ }^{5}$ Several studies have controlled for cross-border smuggling and the findings indicated that price elasticity estimates for the demand of cigarettes still fell into a range of -0.4 to $-0.6,{ }^{56}$ which is comparable with past estimates. In another analysis, Merriman concluded that the tendency of cigarette taxes to deter smoking is not diminished by smuggling. ${ }^{7}$ One of the disadvantages of these studies is that few have relied on individual-level data that assesses actual purchase patterns, which may vary widely within a population, and changes in smoking behaviour in relation to price differentials.

Examples of studies that have relied on individual-level data include a 1999 survey of California adult smokers that indicated that $5.1 \%$ of smokers reported usually purchasing cigarettes from lower or non-taxed venues, including the internet, military bases, or out-of-state vendors. While only $0.3 \%$ avoided the excise tax by usually purchasing cigarettes on the internet, ${ }^{8}$ this source may be more widely utilised more recently. Other lower or no-tax sources for cigarettes are also becoming more popular. A second example is a New Jersey study between 2000 and 2002 that reported the rate smokers usually purchase cigarette on the internet increased by threefold after a 70 cent cigarette excise tax increase, although the rates were still low $(0.8 \%$ in 2000 to $3.1 \%$ in 2002). ${ }^{9}$ In contrast to the relatively lower reported levels of smokers seeking out low or untaxed cigarettes, a recent survey of Western New York adult smokers in 2002-2003 found that $67 \%$ of smokers reported that they usually purchase their cigarettes from an Indian reservation, where the average cigarette price was $40 \%$ that of an off-reservation convenience store and the entire population is within 25 miles of an Indian reservation. ${ }^{10}$ Data from the Community Intervention Trial for Smoking Cessation (COMMIT) indicate that $34 \%$ of smokers aged 38-67 from 20 US communities reported they usually buy cigarettes from a low/untaxed source including another state, an Indian reservation, or the internet, but this ranged from a low of $13 \%$ to a high of $73 \%$ across communities. ${ }^{3}$ Smokers in this study are not nationally or state representative, although they do provide a wide range

Abbreviations: COMMIT, Community Intervention Trial for Smoking Cessation; ITC-4, International Tobacco Control Four Country Survey; NRT, nicotine replacement therapy 
of cigarette tax rates and geographical proximity to less expensive cigarette purchase options. These data confirm that the prevalence of tax avoidance behaviour varies considerably in the population.

In terms of the relationship between using lower priced products and smoking cessation, previous research shows that smokers who switch to discount brands ${ }^{3}$ and those who usually buy their cigarettes from Indian reservations ${ }^{10}$ are less likely to quit, although other studies do not suggest that the availability of lower priced purchase options decreases smoking cessation rates. ${ }^{7}$ Qualitative research in the UK also suggests that low income smokers see the availability of cheap cigarettes as a valued service that helps them continue to access tobacco despite tax increases and may actually add to the appeal of smoking. ${ }^{11}$

Many states and nations have turned to increasing cigarette excise taxes as a way to generate revenue and reduce tobacco consumption. For example, the majority of US states have increased cigarette excise taxes in recent years, and tobacco industry initiated price increases since the Master Settlement Agreement in 1998 have raised cigarette prices even more than the excise tax increases. ${ }^{12}$ In 2000, the cigarette tax in Canada and Australia was more than half of the price of cigarettes while the tax was greater than $75 \%$ of the cigarette price in the UK. ${ }^{13}$ Higher taxes translate into higher prices, and there is a greater incentive for smokers to seek out low/untaxed cigarette sources when the overall retail price has a high fraction from taxes.

If these price increases combine with the relatively easy availability of alternative cheaper sources of tobacco, then consumers will exploit these opportunities. For example, in the UK where high prices are combined with the relatively easy access to both legal and illegal low/untaxed cigarettes from continental Europe, 15\% of the cigarettes smoked in the UK were contraband, and a further $9 \%$ obtained by (legitimate) cross boarder shopping in 2002/3. ${ }^{14}$ By contrast in Australia, despite pronounced price rises over the years, smuggling is rare. This suggests that tax avoidance behaviour is strongest in places where both high prices and ready availability of cheaper products are present.

Relatively few studies have examined the prevalence of these behaviours in representative samples and their impact on smoking cessation indicators. In this study, we report data on cigarette purchase patterns and their relationship with smoking cessation in nationally representative samples of smokers from four countries involved in the International Tobacco Control Four Country Survey (ITC-4). This study has the following objectives: (1) to assess the rate of purchasing less expensive cigarettes by country; (2) to assess characteristics of those who seek out less expensive cigarettes; (3) to assess the relationship between the purchase of less expensive cigarettes and quitting; and (4) to assess the consistency of observed relationships among countries.

\section{METHODS}

\section{Data source}

Participants in Wave 1 of the ITC-4 Survey conducted from October to December 2002 were 9058 current adult ( 18 years of age and older) smokers (defined as having smoked at least 100 cigarettes in their lifetime and currently smoke at least once per month) from Australia, Canada, the United Kingdom, and the United States. The survey fieldwork was conducted using computer-assisted telephone interviews. It was conducted in English, or in French if desired in the francophone areas of Canada. Strict protocols were developed and implemented to ensure equivalence of methods across the four countries. Using a stratified random-digit dialling procedure, households were contacted and screened for adult smokers with the next birthday who would agree to participate in the study. Those who agreed were rescheduled for an in-depth 40-minute phone survey a week later and were sent a cheque to compensate for their time. These participants were asked to respond to questions related to tobacco control policies, smoking behaviour and associated psychosocial predictors. The sample used for Wave 1 crosssectional analyses in the present study includes smokers recruited at Wave 1 , excluding those who had quit since the recruitment survey $(\mathrm{n}=8930)$.

Seven months after the Wave 1 survey, a similar Wave 2 survey was administered to the subjects that completed the Wave 1 survey yielding a total of 6754 participants $(\mathrm{n}=6682$ smokers in Wave 2$)$ in the longitudinal sample who completed both Wave 1 and Wave 2 . To complement the longitudinal sample and to maintain nationally representative cross-sectional samples of smokers, an additional 2054 new smokers were recruited for Wave 2 cross-sectional analyses to replace subjects that were lost to follow-up between Wave 1 and Wave 2 ( $\mathrm{n}=8808$ for Wave 2 crosssectional analyses).

Cooperation rates (the proportion of eligible respondents who completed the survey; Cooperation Rate \#4 from the American Association for Public Opinion Research ${ }^{15}$ ) from the baseline survey wave were high for a survey of this kind: USA 77\%, Canada 79\%, UK 79\%, and Australia 79 $\%{ }^{16}$ and the overall response rates by country were: USA $26 \%$, Canada $50 \%$, UK $38 \%$, and Australia 46\%. A comparison of the descriptive statistics between these two waves of ITC-4 data with other nationally representative surveys of smokers in each of the four ITC-4 countries included shows that respondent demographics and principal responses are comparable. Moreover, comparison of smoking-relevant statistics between the ITC-4 samples and those from other nationally representative surveys demonstrates that the deviation between ITC-4 samples and other surveys are about the same as the deviations between the two previously existing nationally representative surveys themselves, in those three countries in which there are two nationally representative surveys of smokers (the exception being the USA, which only has one nationally representative survey that covers these questions). A full description of the ITC-4 methodology, sample profile, and survey rates, including comparisons with national benchmarks, is available at http://www.itcproject. org.

The study protocol was cleared for ethics by the institutional review boards or research ethics boards in each of the countries: Cancer Council Victoria (Australia), the University of Waterloo (Canada), University of Strathclyde (UK), Roswell Park Cancer Institute (USA), and the University of Illinois-Chicago (USA).

\section{Measure of purchasing cigarettes from low/untaxed venues}

In each wave, the respondents' source of cigarettes at their last purchase was assessed. This was done with the following question: "Where did you last buy cigarettes for yourself?" Subjects who responded that their last source for cigarettes was either an Indian reservation, out of state/ province, a duty-free store, an independent seller, a military commissary, or a toll-free number were defined as having purchased from a low/untaxed venue at their last purchase.

The price per cigarette was calculated based on the selfreported cost and volume of respondent's last cigarette purchase and converted to US dollars. Wave 2 prices were deflated by $2 \%$ to adjust for inflation and to allow for better comparisons between waves. ${ }^{17}$ 


\begin{tabular}{|c|c|c|c|c|c|}
\hline & \multicolumn{4}{|l|}{ Country } & \multirow[b]{2}{*}{ p Value } \\
\hline & $\begin{array}{l}\text { Canada } \\
n=2189\end{array}$ & $\begin{array}{l}\text { USA } \\
n=2102\end{array}$ & $\begin{array}{l}\text { UK } \\
n=2367\end{array}$ & $\begin{array}{l}\text { Australia } \\
n=2272\end{array}$ & \\
\hline \multicolumn{6}{|l|}{ Age in $2002(\%)$} \\
\hline $18-24$ & 14.3 & 15.1 & 14.2 & 16.9 & \multirow[t]{4}{*}{$<0.01$} \\
\hline $25-39$ & 33.7 & 31.3 & 33.0 & 35.7 & \\
\hline $40-54$ & 34.9 & 35.9 & 28.8 & 32.3 & \\
\hline $55+$ & 17.2 & 17.6 & 24.1 & 15.1 & \\
\hline \multicolumn{6}{|l|}{ Race (\%) } \\
\hline White/English only & 88.4 & 74.8 & 94.6 & 86.6 & \multirow[t]{2}{*}{$<0.01$} \\
\hline All other & 11.6 & 25.2 & 5.4 & 13.4 & \\
\hline \multicolumn{6}{|l|}{$\operatorname{Sex}(\%)$} \\
\hline Male & 45.8 & 46.4 & 49.8 & 44.7 & \multirow[t]{2}{*}{0.07} \\
\hline Female & 54.2 & 53.6 & 50.2 & 55.3 & \\
\hline \multicolumn{6}{|l|}{ Income level (\%) } \\
\hline Low & 27.5 & 36.5 & 28.0 & 25.8 & \multirow[t]{4}{*}{$<0.01$} \\
\hline Moderate & 36.8 & 35.3 & 33.7 & 34.8 & \\
\hline High & 27.6 & 21.9 & 28.4 & 33.4 & \\
\hline Refused & 8.0 & 6.4 & 9.9 & 6.0 & \\
\hline \multicolumn{6}{|l|}{ Education level (\%) } \\
\hline Low & 47.8 & 45.3 & 63.5 & 68.0 & \multirow[t]{3}{*}{$<0.01$} \\
\hline Moderate & 39.4 & 43.5 & 24.7 & 20.2 & \\
\hline High & 12.8 & 11.2 & 11.8 & 11.8 & \\
\hline \multicolumn{6}{|l|}{ Smoking status (\%) } \\
\hline Daily & 92.2 & 92.0 & 93.6 & 91.2 & \multirow[t]{3}{*}{0.24} \\
\hline Weekly & 6.9 & 7.1 & 6.1 & 8.1 & \\
\hline Monthly & 0.9 & 0.9 & 0.4 & 0.7 & \\
\hline \multicolumn{6}{|c|}{ No. cigarettes per day (\%) } \\
\hline$<10$ & 30.5 & 30.4 & 29.9 & 27.8 & \multirow{4}{*}{$<0.01$} \\
\hline 11 to 20 & 42.4 & 44.6 & 53.3 & 39.9 & \\
\hline 21 to 30 & 22.5 & 14.3 & 11.8 & 23.7 & \\
\hline$>30$ & 4.6 & 10.6 & 5.0 & 8.6 & \\
\hline \multicolumn{6}{|c|}{ Time to first cigarette (\%) } \\
\hline$\leqslant 5 \mathrm{~min}$ & 16.3 & 17.1 & 17.4 & 19.4 & \multirow[t]{4}{*}{$<0.01$} \\
\hline $6-30 \mathrm{~min}$ & 16.6 & 16.4 & 18.9 & 17.5 & \\
\hline $31-60 \mathrm{~min}$ & 46.5 & 42.0 & 47.5 & 42.8 & \\
\hline$>60 \min$ & 20.6 & 24.5 & 16.2 & 20.3 & \\
\hline \multicolumn{6}{|c|}{ Intention to quit (\%) (in the next month, 6 months, or beyond 6 months) } \\
\hline & 81.1 & 75.1 & 65.3 & 75.6 & $<0.01$ \\
\hline \multicolumn{6}{|l|}{ Ever tried to quit (\%) } \\
\hline Yes & 82.8 & 79.1 & 77.7 & 82.1 & 0.02 \\
\hline
\end{tabular}

\section{Measures of smoking cessation}

Those who reported smoking on at least a monthly basis were defined as smokers at Wave 1. By Wave 2, subjects were defined as a quitter if they reported smoking on less than a monthly basis.

Quit attempts at Wave 2 were assessed with responses to the question, "Have you made any attempts to stop smoking since we last talked with you?" The number of cigarettes smoked per day was determined at each survey wave with the question "On average, how many cigarettes do you smoke each day, including both factory-made and roll-your-own cigarettes?"

\section{Other control variables}

In addition to the above, demographic variables including age ( 18-24 years, 25-39 years, 40-54 years, 55 years and older), sex (male or female), race/ethnicity or language spoken at home (white/English or all others), ${ }^{1}$ time to first cigarette of the day (>60 min, 31-60 min, 6-30 min, $\leqslant 5 \mathrm{~min}$ ), number of cigarettes smoked per day $(<10,11-20,21-30,>30)$, previous attempts to quit smoking (yes or no), educational attainment (low, moderate, high), and income levels (low, moderate, high) were collected. Because of differences in education and monetary systems, the distinct variables for education and income for each country were combined into one variable for each so that comparisons could be made between countries.

\section{Statistical analyses}

Descriptive statistics by country are presented and differences are assessed using the $\chi^{2}$ test for independence. The characteristics of those who purchased low/untaxed sources and cessation indicators were assessed using logistic regression. Logistic regression was also used to assess how the purchase of low/untaxed cigarettes was related to smoking cessation indicators. In addition, we examined potential differences in the percentage who reported buying from low/ untaxed sources in the continuing cohort sample and the new replenishment sample obtained in Wave 2, and the results were similar; therefore, subsequent analyses combined these two types of respondents and treated their survey data equally.

The characteristics of the ITC- 4 cohort by country are described in table 1 . Over half of the respondents from Australia were under the age of 40 , while most of the respondents from the other three countries were 40 years old and older. The UK had the largest percentage of respondents who were white only, and the USA had the largest percentage of non-white respondents. Overall, the percentage of females was slightly greater than the percentage of males. In each country, more smokers consumed between 11-20 cigarettes per day compared to other categories, and approximately $80 \%$ had ever tried to quit smoking. 
Table 2 Percentage of subjects reporting the source for their last purchase of cigarettes by country in Wave 1 and Wave 2

\begin{tabular}{|c|c|c|c|c|c|c|c|c|}
\hline & \multicolumn{2}{|l|}{ Canada } & \multicolumn{2}{|l|}{ USA } & \multicolumn{2}{|l|}{ UK } & \multicolumn{2}{|l|}{ Australia } \\
\hline & Wave 1 & Wave 2 & Wave 1 & Wave 2 & Wave 1 & Wave 2 & Wave 1 & Wave 2 \\
\hline Low/untaxed sources & $\%$ & $\%$ & $\%$ & $\%$ & $\%$ & $\%$ & $\%$ & $\%$ \\
\hline Indian reservation & 2.0 & 2.4 & 2.6 & 3.2 & 0.0 & 0.0 & 0.0 & 0.0 \\
\hline Duty free & 0.6 & 0.7 & 0.4 & 0.2 & 4.1 & 5.6 & 0.7 & 0.6 \\
\hline Out of state/province & 0.2 & 0.3 & 0.4 & 0.3 & 8.7 & 10.6 & 0.0 & 0.2 \\
\hline Military commissary & 0.0 & 0.0 & 0.8 & 1.0 & 0.0 & 0.0 & 0.0 & 0.0 \\
\hline Toll-free number & 0.0 & 0.0 & 0.0 & 0.1 & 0.0 & 0.0 & 0.0 & 0.0 \\
\hline Internet & 0.0 & 0.0 & 0.6 & 1.3 & 0.0 & 0.1 & 0.0 & 0.1 \\
\hline Independent seller & 0.3 & 0.3 & 0.1 & 0.0 & 2.5 & 3.3 & 0.0 & 0.3 \\
\hline Total low/untaxed sources* & 3.1 & 3.7 & 4.8 & 6.1 & 15.3 & 19.7 & 0.7 & 1.1 \\
\hline Average per cigarette price (in US\$) † & 0.13 & 0.15 & 0.10 & 0.12 & 0.16 & 0.19 & 0.08 & 0.11 \\
\hline Full-priced sources & $\%$ & $\%$ & $\%$ & $\%$ & $\%$ & $\%$ & $\%$ & $\%$ \\
\hline Gas station, convenience store & 71.2 & 73.7 & 61.7 & 66.1 & 27.8 & 24.2 & 21.9 & 19.0 \\
\hline Grocery & 17.2 & 16.3 & 12.7 & 12.6 & 35.8 & 34.9 & 52.6 & 53.0 \\
\hline Discount store & 6.3 & 5.4 & 4.7 & 4.4 & 0.6 & 0.2 & 1.0 & 1.0 \\
\hline Bar & 0.3 & 0.3 & 0.5 & 0.6 & 1.4 & 1.5 & 2.4 & 1.8 \\
\hline Vending & 0.2 & 0.1 & 0.0 & 0.0 & 0.5 & 0.2 & 0.5 & 0.2 \\
\hline Tobacconist & 0.5 & 0.0 & 0.4 & 0.1 & 2.3 & 2.5 & 12.1 & 13.0 \\
\hline News stand & 0.0 & 0.0 & 0.0 & 0.0 & 3.9 & 1.6 & 0.5 & 0.3 \\
\hline Newsagent & 0.0 & 0.0 & 0.0 & 0.0 & 12.0 & 14.5 & 2.9 & 3.2 \\
\hline Milkbar & 0.0 & 0.0 & 0.0 & 0.0 & 0.1 & 0.1 & 4.0 & 6.6 \\
\hline Smoke shop & 1.2 & 0.6 & 12.4 & 7.8 & 0.1 & 0.0 & 0.2 & 0.0 \\
\hline Liquor store & 0.2 & 0.0 & 2.8 & 2.3 & 0.3 & 0.6 & 1.2 & 0.8 \\
\hline Total full-priced sources & 96.9 & 96.4 & 95.2 & 93.9 & 84.7 & 80.3 & 99.3 & 98.9 \\
\hline Average per cigarette price (in US\$)* & 0.20 & 0.23 & 0.17 & 0.23 & 0.31 & 0.35 & 0.19 & 0.20 \\
\hline
\end{tabular}

*There was a significant difference between the Wave 1 and Wave 2 rate of purchase from a low/untaxed source for the UK. There were no significant differences between Wave 1 and Wave 2 rates of low/untaxed purchase for any other country.

†Prices adjusted to 2002 US dollars.

\section{RESULTS}

\section{Source of last cigarette purchase}

As shown in table 2, the most frequently cited location for smokers' last cigarette purchase was a convenience store or gas station in Canada and the USA, while the most frequently named source was a grocery store in Canada and the UK. In three of the countries (Australia, Canada and the USA) at Wave 1 a relatively small percentage of smokers reported their last cigarette purchase was from a low/untaxed source, but in the UK a significant proportion did (15\% at Wave 1). Furthermore, the pattern remained the same in the first three countries, while it increased in the UK to $20 \%$ ( $p<0.01$ for z-test of difference of proportions) in the UK. The price per cigarette was lowest in the USA and Australia and was about twice as high in the UK.

\section{Characteristics of smokers purchasing low/untaxed cigarettes}

Table 3 shows the characteristics of smokers who reported purchasing cigarettes from low/untaxed sources in their last purchase from the Wave 1 survey. Smokers who reported purchasing cigarettes from low/untaxed sources were more likely to be from the UK, be older, be white or speak English at home, have higher incomes, and have greater education. Surprisingly, cigarettes smoked per day was not associated with buying low/untaxed cigarettes on their last purchase.

\section{Low/untaxed cigarettes and future smoking cessation}

As shown in table 4, those who reported purchasing from a low/untaxed source in their last purchase attempt at Wave 1 had lower rates of making a quit attempt by Wave 2 compared to those who had not purchased from a low/ untaxed source at Wave 1 (overall relative risk (RR) 0.70, $\mathrm{p}<0.01)$. No significant pattern was observed for quitting among those who bought from a low/untaxed sources at Wave 1, although the point estimate was less than one in the three countries where these purchase patterns are more common (in Canada, RR 0.57, p = 0.36; in the USA, RR 0.72, $\mathrm{p}=0.54$; in the UK, RR 0.87, $\mathrm{p}=0.55$; in Australia,
RR 4.87, $\mathrm{p}<0.01)$. For both outcomes, there was a significant interaction between the report of buying from a low/untaxed source and country with the results from Canada, USA, and UK trending in the predicted direction and results from Australia trending in the opposite direction. One explanation for this is that Australian smokers rarely purchase cigarettes from low/untaxed sources and the number of observations in the sample is small.

\section{DISCUSSION}

Data from this study indicate that a sizeable fraction of smokers report purchasing cigarettes from low/untaxed sources and this behaviour decreases the likelihood of making a quit attempt. The availability of low/untaxed cigarettes may undermine the public health benefit of increased cigarette excise taxes.

One finding that may be somewhat surprising is that those with higher incomes were more likely to report buying cigarettes from low/untaxed sources. This is consistent, however, with a study of smokers throughout the USA ${ }^{3}$ and may indicate that a minimum set of resources is needed to purchase low/untaxed cigarettes that may require travel or internet access. Also surprising was that cigarettes per day was not a significant predictor of purchasing low/untaxed cigarettes. This suggests that smokers, regardless of how much they smoke, will take advantage of opportunities to purchase lower priced products.

The higher rates of low/untaxed purchases in the UK is likely a function of high cigarette prices that fuel unregulated cigarette resellers, while the low rates observed in Australia are due to its relative isolation and national-level cigarette taxation policy. In Canada and the USA, cross-provincial/ state sales and low/untaxed cigarette purchases from Indian reservations that are unique to these nations contribute to this behaviour.

Focusing on the UK, cigarettes are relatively expensive (about twice the cost of US cigarettes), which suggests high prices drive low/untaxed cigarette purchases. However, these data suggest that availability is another critical factor, which 
Table 3 Characteristics of smokers who purchased from low/untaxed sources at their last purchase from the Wave 1 survey $(n=8930)$

\begin{tabular}{|c|c|c|c|c|}
\hline & $\mathrm{n}$ & $\%$ & OR & $95 \% \mathrm{Cl}$ \\
\hline \multicolumn{5}{|l|}{ Country } \\
\hline Canada & 2189 & 3.1 & 1.00 & Referent \\
\hline USA & 2102 & 4.8 & 1.72 & 1.07 to 2.78 \\
\hline UK & 2367 & 15.3 & 6.33 & 3.91 to 10.27 \\
\hline Australia & 2272 & 0.7 & 0.32 & 0.10 to 0.98 \\
\hline \multicolumn{5}{|l|}{ Age in 2002} \\
\hline $18-24$ & 1246 & 2.8 & 1.00 & Referent \\
\hline $25-39$ & 2945 & 4.9 & 1.67 & 1.14 to 2.45 \\
\hline $40-54$ & 3024 & 7.0 & 2.48 & 1.71 to 3.60 \\
\hline $55+$ & 1715 & 10.3 & 3.63 & 2.47 to 5.32 \\
\hline \multicolumn{5}{|l|}{ Race } \\
\hline White/English only & 7723 & 7.1 & 1.00 & Referent \\
\hline All other & 1195 & 3.0 & 0.60 & 0.44 to 0.82 \\
\hline \multicolumn{5}{|l|}{ Sex } \\
\hline Female & 4892 & 6.5 & 1.00 & Referent \\
\hline Male & 4038 & 6.1 & 0.95 & 0.79 to 1.14 \\
\hline \multicolumn{5}{|l|}{ Income level } \\
\hline Low & 2758 & 5.1 & 1.00 & Referent \\
\hline Moderate & 3038 & 6.5 & 1.30 & 1.03 to 1.64 \\
\hline High & 2407 & 7.9 & 1.51 & 1.17 to 1.95 \\
\hline Refused & 679 & 5.9 & 0.87 & 0.58 to 1.32 \\
\hline \multicolumn{5}{|l|}{ Education level } \\
\hline Low & 4987 & 6.0 & 1.00 & Referent \\
\hline Moderate & 2770 & 6.2 & 1.33 & 1.08 to 1.64 \\
\hline High & 1136 & 7.8 & 1.45 & 1.08 to 1.93 \\
\hline \multicolumn{5}{|l|}{ No. cigarettes per day } \\
\hline$<10$ & 2810 & 5.1 & 1.00 & Referent \\
\hline $11-20$ & 4010 & 6.6 & 1.11 & 0.86 to 1.42 \\
\hline $21-30$ & 1533 & 7.7 & 1.33 & 0.96 to 1.85 \\
\hline$>30$ & 574 & 6.6 & 1.25 & 0.85 to 1.83 \\
\hline \multicolumn{5}{|l|}{ Time to first cigarette } \\
\hline$>60 \mathrm{~min}$ & 1666 & 5.0 & 1.00 & Referent \\
\hline $31-60 \mathrm{~min}$ & 1552 & 7.5 & 1.34 & 0.96 to 1.86 \\
\hline $6-30 \mathrm{~min}$ & 3875 & 6.1 & 0.97 & 0.71 to 1.33 \\
\hline$\leqslant 5 \min$ & 1758 & 6.5 & 1.22 & 0.86 to 1.73 \\
\hline \multicolumn{5}{|l|}{ Past quit attempts } \\
\hline No & 1715 & 6.3 & 1.00 & Referent \\
\hline Yes & 7194 & 6.3 & 0.95 & 0.75 to 1.20 \\
\hline
\end{tabular}

Respondents were considered to be "low/untaxed" purchasers if they reported that the last place they purchased cigarettes was either: an Indian reservation, out of state/province, a duty-free store, an independent seller, the internet, a military commissary, or a toll-free number.

may explain why the rates of low/untaxed cigarette purchasing are so low in geographically isolated Australia. The significant increase in cheaper cigarette sources at the last purchase between Waves 1 and 2 in the UK took place at a time when tax increases were indexed to inflation, ${ }^{18}$ so price increases cannot explain the change. On the other hand, the timing of fieldwork may provide the explanation. The Wave 2 interviewing took place in the UK's summer holiday season when respondents would have been much more likely to visit the continent where access to low/untaxed cigarettes is available compared with Wave 1, which took place late in the European autumn. Thus availability and high prices together appear to be the key factors. This provides empirical evidence to support the tobacco control argument that the correct response to reduced pricing differentials is not to reduce prices to the lowest common denominator, but rather increase prices to a high and uniform level and to reduce access to cheaper products.

Another factor to consider is that cigarettes are generally inexpensive and unregulated by federal authorities in each country. In contrast, stop smoking medications such as nicotine replacement therapy (NRT), which boost cessation rates, are generally more expensive, more difficult to access, and subject to a far reaching array of regulatory policies that cigarettes are not required to adhere to. ${ }^{19}$ Reducing price differentials between cigarettes and NRT could result in higher rates of NRT utilisation in the face of higher cigarette prices.

In three countries, our point estimates show that those who purchased at low/untaxed sources had lower rates of making a quit attempt or quitting successfully between Waves 1 and 2 than those who did not purchase from low/ untaxed sources, while the relative risk for making a quit attempt $(\mathrm{p}<0.01)$ and quitting $(\mathrm{p}=0.06)$ in Australia was higher. The Australian data are interesting; however, the sample is limited because low/untaxed cigarettes are rare and the characteristics of these purchasers in Australia may differ from those in other countries where this behaviour is more common in ways we have not measured in the survey. For example, almost all of the low/untaxed purchases in Australia were done through duty-free shops whereas this was a relatively minor source in the other three countries. This observation warrants additional consideration.

Although it is difficult to sort out all of the relationships with only two survey waves, it is reasonable to speculate that access to low taxed cigarettes reduces eventual quit success. Data from other studies reinforces this hypothesis. For example, data from a study in Western New York State found that making efforts to obtain low taxed cigarettes from

Table 4 Likelihood of smoking cessation and cessation attempts at Wave 2 by purchase of low/untaxed cigarettes at Wave 1 $(n=6682)$

\begin{tabular}{|c|c|c|c|c|c|c|c|c|c|}
\hline \multirow[b]{2}{*}{ Country } & \multirow{2}{*}{$\begin{array}{l}\text { "Low/untaxed" source at } \\
\text { last purchase Wave } 1\end{array}$} & \multirow[b]{2}{*}{$\mathbf{n}$} & \multirow[b]{2}{*}{$\%$} & \multicolumn{3}{|c|}{ Quit smoking-Wave 2} & \multicolumn{3}{|c|}{ Quit attempt-Wave 2} \\
\hline & & & & $\%$ & $\mathbf{R R}$ & p Value & $\%$ & $\mathbf{R R}$ & p Value \\
\hline \multirow[t]{2}{*}{ Overall } & No & 6224 & 93.8 & 9.0 & 1.00 & Ref & 37.1 & 1.00 & Ref \\
\hline & Yes & 458 & 6.2 & 8.1 & 0.93 & 0.71 & 26.2 & 0.70 & $<0.01$ \\
\hline \multirow[t]{2}{*}{ Canada } & No & 1613 & 97.1 & 10.8 & 1.00 & Ref & 44.4 & 1.00 & Ref \\
\hline & Yes & 52 & 2.9 & 5.8 & 0.57 & 0.36 & 28.8 & 0.49 & 0.02 \\
\hline \multirow[t]{2}{*}{ USA } & No & 1247 & 95.4 & 8.4 & 1.00 & Ref & 36.9 & 1.00 & Ref \\
\hline & Yes & 82 & 4.6 & 4.9 & 0.72 & 0.54 & 28.0 & 0.85 & 0.55 \\
\hline \multirow[t]{2}{*}{ UK } & No & 1533 & 84.2 & 9.3 & 1.00 & Ref & 32.7 & 1.00 & Ref \\
\hline & Yes & 304 & 15.8 & 7.9 & 0.87 & 0.55 & 23.4 & 0.63 & $<0.01$ \\
\hline \multirow[t]{2}{*}{ Australia } & No & 1831 & 99.1 & 7.6 & 1.00 & Ref & 33.9 & 1.00 & Ref \\
\hline & Yes & 20 & 0.9 & 30.0 & 4.87 & $<0.01$ & 55.0 & 2.37 & 0.06 \\
\hline
\end{tabular}

Logistic regression models predicting indicators of cessation as a function of cheaper purchase controlling for age, ethnicity, sex, income, education, number of cigarettes per day, time to first cigarette, and past quit attempts.

Respondents were considered to be "low/untaxed" purchasers if they reported that the last place they purchased cigarettes was either: an Indian reservation, out of state/province, a duty-free store, an independent seller, the internet, a military commissary, or a toll-free number.

Table 4 is restricted to the cohort of respondents who were smokers at Wave 1 and completed the Wave 2 survey. Therefore, the percentage who purchased from a low/untaxed source at Wave 1 is different in table 4, compared to tables 2 and 3 . Sample sizes presented in the table are unweighted, and percentages are from weighted data.

There were significant country by "cheaper cigarette purchase" interactions at the $5 \%$ level for quitting and for quit attempts. 


\section{What this paper adds}

This is one of the few papers to provide an international comparison of cigarette purchase patterns. Results show wide variation in the prevalence of the purchase of low/untaxed cigarette sources by country. Results show that there are lower levels of making smoking cessation attempts among purchasers of low/untaxed cigarettes compared to purchasers of full-priced cigarettes. The availability of low/untaxed cigarettes may mitigate the influence of increases in cigarette prices.

Indian reservations was associated with making fewer quit attempts and possibly lower cessation rates. ${ }^{3}$ Cummings et al found that smokers who avoid higher cigarette prices by switching to discount/generic cigarette brands are less likely to stop smoking or to reduce cigarette consumption. ${ }^{4}$

Similar associations were found in three of the four countries, with Australia being the outlier in terms of the relationship between purchasing low/untaxed cigarettes and cessation behaviour. We looked at the country by cheaper purchase measure interaction for cessation and cessation attempts and observed a significant relationship for quit attempts and successful cessation. Further study is needed to fully understand this result; however, the similarity of findings across the three countries with a wider array of sources of low/untaxed cigarettes suggests these results may generalise to other countries with similar market structures that are not represented in this study.

The main strengths of this study are the large sample of smokers, the detail of the purchase patterns queried, and the geographic diversity of subjects from four different countries. An important limitation is that the duration to follow-up was only seven months, which yields relatively few quitters; however, an overall significant association was observed despite this limitation. This paper focuses on the purchase of low/untaxed cigarettes in the face of higher prices. Smokers can also alter their behaviour in other ways to compensate for high prices. For example, they may switch to discount/generic cigarettes, reduce their consumption, or smoke their cigarettes more efficiently. Subsequent analyses of ITC-4 data will explore these possibilities.

The availability of low/untaxed cigarettes may undermine the public health benefit of higher cigarette excise taxes by giving price sensitive smokers, who might have quit otherwise, product options within their budget. Thus, interventions that reduce the availability of cheaper products are suggested as a means to maximise the public health benefit of cigarette excise taxes.

\section{ACKNOWLEDGEMENTS}

We wish to thank Ruth Loewen and Pete Driezen for data management. The research was funded by grants from the US National Cancer Institute/NIH (from the Roswell Park Transdisciplinary Tobacco Use Research Center (TTURC), P50 CAll1236, and from R01 CAl00362), the Canadian Institutes for Health Research (57897), Robert Wood Johnson Foundation (045734), the Australian National Health and Medical Research Council (265903), Cancer Research UK (C312/A3726), the Australian Commonwealth Department of Health and Ageing, the Centre for Behavioural Research and Program Evaluation of the National
Cancer Institute of Canada/Canadian Cancer Society, and the Canadian Tobacco Control Research Initiative.

\section{Authors' affiliations}

A Hyland, C Higbee, K M Cummings, Roswell Park Cancer Institute, Department of Health Behavior, Buffalo, New York, USA

F L Laux, Department of Business Administration, North Eastern State University (NSU) College of Business and Technology, Tahlequah,

Oklahoma, USA

G Hastings, University of Stirling and the Open University, Stirling, UK H Ross, RTI International, Research Triangle Park, North Carolina, USA

F J Chaloupka, Department of Economics, University of Illinois at Chicago, Chicago, Illinois, USA

G T Fong, Department of Psychology, University of Waterloo, Waterloo, Ontario, Canada

Competing interests: none declared

Ethics approval: The study protocol was cleared for ethics by the Institutional Review Boards or Research Ethics Boards in each of the countries: the University of Waterloo (Canada), Roswell Park Cancer Institute (USA), the University of Illinois-Chicago (USA), the University of Strathclyde (UK), and The Cancer Council Victoria (Australia).

\section{REFERENCES}

1 Chaloupka FJ, Cummings KM, Morley CP, et al. Tax, price and cigarette smoking: evidence from the tobacco documents and implications for tobacco company marketing strategies. Tob Control 2002;11(suppl I):i62-72.

2 Emery S, White MM, Gilpin EA, et al. Was there significant tax evasion after the 199950 cent per pack cigarette tax increase in California? Tob Control 2002;11:130-4.

3 Hyland A, Baver JE, Li Q, et al. Higher cigarette prices influence cigarette purchase patterns. Tob Control 2005;14:86-92.

4 Cummings KM, Hyland A, Lewit $E$, et al. Use of discount cigarettes by smokers in 20 communities in the United States, 1988-1993. Tob Control 1997;6(suppl):S25-30.

5 Yurekli AA, Zhang P. The impact of clean indoor-air laws and cigarette smuggling on demand for cigarettes: an empirical model. Health Economics 2000;9:159-70.

6 Gruber J, Sen A, Stabile M. Estimating price elasticities when there is smuggling: the sensitivity of smoking to price in Canada. Journal of Health Economics 2003;22:821-42.

7 Merriman D. Cigarette smuggling does not reduce the public health benefits of cigarette taxes. Applied Economics Letters 2002;9:493-6.

8 Emery S, White MM, Gilpin EA, et al. Was there significant tax evasion after the 199950 cent per pack cigarette tax increase in California? Tobacco Control 2002;11:130-4.

9 Hrywna M, Delnevo CD, Staniewska D. Prevalence and correlates of internet cigarette purchasing among adult smokers in New Jersey. Tob Control 2004; 13:296-300.

10 Hyland A, Higbee C, Baver J, et al. Cigarette purchasing behaviors when prices are high. Journal of Public Health Management and Practice 2004; 10:497-500.

11 Wiltshire S, Bancroft A, Amos A, et al. They're doing people a service-a qualitative study of smoking, smuggling and social deprivation. BMJ 2001;323:203-7.

12 The National Center for Tobacco-Free Kids. U.S. Cigarette company price increases 1993-2002. 21 June, 2002.

13 World Health Organization. The tobacco atlas, http://www. who.int/ tobacco/statistics/tobacco_atlas/en/print.html (Accessed 15 Dec 200)

14 HM Customs \& Excise. Revenue evaded and avoided. In: Tobacco Factsheet February 2005. HM Revenue \& Customs Statistics and Analysis of Trade Unit (SATU). Online, http://www.uktradeinfo.com/index.cfm?task = facttobac (Accessed 13 April 2005).

15 American Association for Public Opinion Research. Standard definitions: final dispositions of case codes and outcomes rates for survey, 2000. http://www.aapor.org/default.asp?page = survey_methods/ standards_and_best_practices/standard_definitions.

16 Hammond D, Fong GT, Thompson M, et al. ITCPES Wave 1 Technical Report. http://www.itcproject.org (Accessed 23 Dec 2004).

17 OANDA. The currency site, http://www.oanda.com/convert/classic (Accessed 11 Sept 2004).

18 Anon. Financial Times, Apr 10, 2003.

19 Jha P, Chaloupka FJ. The economics of global tobacco control. BMJ 2000;321:358-61. 